University of Louisville

ThinkIR: The University of Louisville's Institutional Repository

\title{
"Y'all and all these assessments is a little bit too much" : the effects of high-stakes testing on critical literacy pedagogy.
}

\author{
Diana Lalata \\ University of Louisville
}

Follow this and additional works at: https://ir.library.louisville.edu/honors

Part of the Bilingual, Multilingual, and Multicultural Education Commons, Civil Rights and

Discrimination Commons, Curriculum and Instruction Commons, Curriculum and Social Inquiry

Commons, Educational Assessment, Evaluation, and Research Commons, Educational Methods

Commons, English Language and Literature Commons, Language and Literacy Education Commons,

Linguistics Commons, Secondary Education Commons, and the Teacher Education and Professional

Development Commons

\section{Recommended Citation}

Lalata, Diana, "'Y'all and all these assessments is a little bit too much" : the effects of high-stakes testing on critical literacy pedagogy." (2017). College of Arts \& Sciences Senior Honors Theses. Paper 137.

http://doi.org/10.18297/honors/137

This Senior Honors Thesis is brought to you for free and open access by the College of Arts \& Sciences at ThinkIR: The University of Louisville's Institutional Repository. It has been accepted for inclusion in College of Arts \& Sciences Senior Honors Theses by an authorized administrator of ThinkIR: The University of Louisville's Institutional Repository. This title appears here courtesy of the author, who has retained all other copyrights. For more information, please contact thinkir@louisville.edu. 
"Y'all and All These Assessments is a Little Bit Too Much":

The Effects of High-Stakes Testing on Critical Literacy Pedagogy

Senior Honors Thesis Presented

by

Diana Lalata

to

The Committee on University Honors Theses

in partial fulfillment of the requirements

for a degree with Summa Cum Laude Honors

of Bachelor of Arts

Department of English

College of Arts and Sciences

May 2017 


\begin{abstract}
As the United States of America becomes increasingly diverse, there is a need for teachers to embrace multiculturalism within the classroom. Shifting away from the traditional "banking model" of teaching, educational researchers call for a more critical approach-one in which teachers and students challenge dominant beliefs and practices of education. Foregrounded in those aims of cultural competence and critical consciousness, "critical literacy pedagogy" addresses the politicization of literacy education and employs conscious curriculum and teaching strategies to empower marginalized voices. Although a number of case studies on critical literacy pedagogy show considerable promise in disrupting dominant discourse and developing cultural understanding, there has been little research on how high-stakes testing affects the teacher's practice of critical literacy. This qualitative case study explored how a teacher implemented critical literacy pedagogy in an 11th grade English Language Arts classroom. Findings revealed that the teacher was restricted in consistently teaching from a critical literacy perspective as the pressures of high-stakes testing required more emphasis on grammar instruction. This study not only illustrates critical literacy as multifaceted, presenting several strategies for English teachers to exercise the pedagogy, but also points to the challenges in negotiating high-stakes testing and the representations of social power through language and literature.
\end{abstract}




\section{Biography}

Diana Lalata is a senior at the University of Louisville studying English and Political Science, with minors in Spanish and Social Change, and a certificate in Peace Studies, Justice and Conflict Transformation. She has volunteered and worked within a variety of educational settings, serving roles as a tutor and teacher for non-profit organizations and the Jefferson County Public School System in Louisville, Kentucky. Lalata is passionate about educational equity, which informed the focus of her study. 


\section{Acknowledgements}

I would like to give a special thank you to the advisor of my thesis, Dr. Olinger, for her mentorship throughout the entire research process. I have learned much from her guidance and expertise within my chosen area of study, for which I am extremely grateful. I am grateful for the support of my family and friends, who offered advice and assistance whenever needed. In addition, I am indebted to the many individuals and mentors along the way who have offered academic resources concerning the topic of my thesis and important insight to push my study further. Last, but not least, I would like to thank the faculty, staff, and students who participated in the case study. The time spent during observation hours and the rich and engaging conversations with my teacher and students taught me more than I would have ever imagined. 
"Let's make America great again, shall we?” Mr. Walker said sarcastically to his students as they walked through the door on the day after the 2016 presidential election. Just like any other day, each student picked up a copy of the daily assignment from the podium staged at the front of the classroom, but this day offered a unique writing prompt: "Donald Trump is President. You will write him a letter. Express your hopes and fears for the next 4 years. Do you support him? Why/why not? What does his election make you feel about our nation?" A collective groan reverberated around the room, with some students expressing their fears of a "racial civil war" and others refusing to "go back to slavery." Other students immediately channeled their emotions into writing, withdrawing from the political discussion entirely. As a participant observer, I walked around the classroom to listen to conversations and survey the students' writing. One student, Marcus, particularly caught my attention. Marcus sat with a blank sheet of paper on his desk and watched as most of his peers were either furiously engaged in debate or writing. When I asked Marcus why he did not start his letter, he looked forward with a gaze of indifference and responded, "Why do people even care who's president?"

I probed Marcus further, arguing that those who hold political leadership positions can make a huge impact on the outlook of his future. Unconvinced, Marcus fired back that he did not care as long as he received money: "If Donald Trump paid me $\$ 500$ a day to pick cotton, I would work sun up to sun down, and I wouldn't care if he was president or not." Marcus's statement drew attention from a nearby student, Nia, who turned around in her seat and expressed her disbelief, "Are you crazy? What would your ancestors say about that? They worked in fields, so we wouldn't have to." The comment became a classroom dispute—students looked up from their letters to listen to Nia explain why she felt Marcus's statement was problematic, as she indicated that the mere act of picking cotton would be "a disgrace to the African-American race." 
Although the argument was left unresolved, the exchange displayed a prime example of one of the many existing ramifications of racism within the United States to disenfranchise students from taking ownership of their power by inducing an atmosphere of political apathy. Marcus refused to accept the historical significance of reverting to such work and stood firmly in his mission for money, while Nia established her desire to go to college and choose a career that would stray away from work reminiscent of slavery. My following interactions with the students were framed by my curiosity about when and where students like Marcus began to feel as if they could not - or did not—want to participate in society, and what factors played a role in the process of the disenfranchisement of students of color. During the Civil Rights Movement and continuing into the post-Civil Rights era, education researchers focused on such issues, and devised solutions by naming and developing teaching strategies such as "Culturally Relevant Pedagogy" and "Critical Literacy Pedagogy." Inspired by Paulo Freire's aim of "Critical Pedagogy" to liberate students from the chains of oppression and encourage active citizenry, culturally relevant and critical literacy pedagogies sought to connect critical consciousness, culture, and constructs of language within the classroom in order to disrupt the dominant discourse of "Whiteness" and promote a multicultural perspective within the politicization of literacy education (Chubbuck, 2004; Freire, 2000; Godley and Loretto, 2013; Janks et al., 2013; Morell, 2008).

Education research on culturally relevant and critical literacy pedagogies has helped preservice and in-service teachers to reform traditional modes of teaching which are seen as unfit for the growing multiculturalism of the United States. Most literature on implementing culturally relevant and critical literacy pedagogies presents both benefits and drawbacks to these practices, but some lack substantial discussion of the evident obstacle of high-stakes testing for teachers 
implementing critical literacy pedagogy and socially just education in an age of accountability (Borsheim-Black, 2015; Delpit, 1986; Godley, et al., 2007; Godley and Loretto, 2013; LadsonBillings, 1995; Rouland, et al., 2014; Young, 2010). Although research within critical literacy pedagogy mention high-stakes testing as a potential difficulty, there is little discussion of how teachers balance this pedagogy with the demands of testing. Thus, my research seeks to answer the following question: How does a teacher invested in critical literacy negotiate the pressures of high-stakes testing?

This case study of an $11^{\text {th }}$ grade English Language Arts classroom at Riverdale High School ${ }^{1}$ finds that a teacher's critical literacy pedagogy, situated within a multicultural school setting, may be hindered by high-stakes testing because of an overemphasis of "Dominant American English" grammar instruction to students whose home languages do not reflect the dominant culture (Paris, 2012). ${ }^{2}$ First, I present a review of the literature on culturally relevant pedagogy, critical literacy, and high-stakes testing. Then, I describe the methods of my ethnographic case study conducted at Riverdale High School. Finally, I present my findings on the political, social, and cultural obstacles which restrict the potential of critical literacy pedagogy in effecting social change.

\section{Unpacking "Culturally Relevant Pedagogy" and "Critical Literacy"}

Both culturally relevant and critical literacy pedagogies ware inspired by Paulo Freire's concept of "critical pedagogy," which presents a way of teaching that encouraged teachers and students to question the dominant beliefs and practices of education posited by oppressors (Freire, 2000). This concept rejects the traditional model of teaching, referred to as the "Banking

\footnotetext{
${ }^{1}$ Riverdale High School is a pseudonym for the school site.

2 In Paris' article, 'Culturally Sustaining Pedagogy: A needed change in stance, terminology, and practice," the term "Dominant American English" is used in place of "Standard American English" to eliminate the idea that there is a language "standard."
} 
Method," a metaphor which treats teachers as depositors of information and students as banking institutions that reserve the received deposits (Freire, 2000). Critical pedagogy challenges the uneven power structure that exists within the "banking model": teachers and students are encouraged to question one another and the institutions that influence learning in order to create a classroom environment which values active participation in the teaching and learning exchange (Freire, 2000). As a result, this pedagogy holds potential to effect social change by developing within individuals a critical consciousness. This aim of fostering active citizens laid the foundation for many education researchers to build their own pedagogies which align with Freire's mission of eradicating systems of oppression through education.

Culturally relevant pedagogy fuses critical consciousness with cultural understanding. According to Ladson-Billings, culturally relevant pedagogy is intended to allow marginalized students, such as those of color, to take ownership of how and what they learn in the classroom in order to develop active citizenry (Ladson-Billings, 1995). To inform the practices of teachers, this pedagogy encourages a deep understanding of cross-cultural differentiation and the questioning of social assumptions of power in the classroom and society. The expectations for students guided by culturally relevant pedagogy include:

(a) students must experience academic success; (b) students must develop and/or maintain cultural competence; (c) students must develop a critical consciousness through which they challenge the status quo of the current social order (Ladson-Billings, 1992, p. 314).

The standards of culturally relevant pedagogy add to those of critical pedagogy an increased interest in the way that teachers navigate their own cultural identities as well as their students'. In the classroom, culturally relevant pedagogues engage in using "student culture as the basis for 
helping students understand themselves and others, structure social interactions, and conceptualize knowledge" (Ladson-Billings, 1992, p. 314). In "Reading Between the Lines and Beyond the Pages: A Culturally Relevant Approach to Literacy Teaching,” Ladson-Billings pinpoints the social and political purposes of literacy and the notion that depending on the instructional method, a teacher can either maintain the status-quo, or seek to disrupt the dominant discourse (Ladson-Billings, 1992).

Pushing culturally relevant pedagogy further, critical literacy is a teaching perspective grounded in those ideals of social and cultural consciousness, yet focuses specifically on the relationship of curriculum and classroom management choices of the teacher in order to address the needs of students who have traditionally been excluded from attaining literacy education, such as urban youth of color, who have historically been denied the civil right of literacy (Giroux, 1993). The "critical literacy practice" draws upon the understanding that literacy education is indeed political as it has sustained oppression, but also can lead to empowerment (Giroux, 1993). Although literacy education may seem apolitical on the surface level, it is evident that texts carry certain ideologies and promote specific world views. Thus, critical literacy encourages students to develop critical consciousness through a number of strategies: to view literature and other texts from a critical perspective by identifying implicit or explicit bias in favoring one culture over another, to question their own beliefs and biases, and to confront cultural assimilation through celebrating diversity in language and literature.

In order to do so, critical literacy pedagogues advise teachers to provide a variety of texts apart from the dominant discourse for "resistance reading" and students to "engage in dialogue through their own written and oral voices, giving them the capacity to transform the communities, society, and world in which they live" (Giroux, 1993, p. 220). In empowering 
marginalized voices, critical literacy acknowledges that language and grammar play a role in sustaining the social power of certain groups while oppressing others (Morell, 2008). Not only do teachers illustrate critical literacy pedagogy through studying texts which represent various cultures, but do so in a way that "bridges in-school academic curriculum and out-of-school youth literary practices" (Hill, 2009; p. 18). This practice has been researched and refined as "hip-hopbased education," which moves beyond traditional grammar instruction of Dominant American English and embraces hip-hop culture and African-American Language (Hill, 2009; Morell, 2008). Although the implementation of critical literacy pedagogy may look different from teacher to teacher, the literature revealed that these pedagogies can disrupt the dominant discourse of Whiteness, develop cultural understanding instead of assimilation, and politicize literacy education in a way that inspires teachers and students to question structures of oppression (Borsheim-Black, 2015; Chubbuck, 2004; Freire, 2000; Giroux, 1993; Godley and Loretto, 2013; Janks et al., 2013; Ladson-Billings, 1992; Morell, 2008). Critical literacy, as well as critical and culturally relevant pedagogies, are all necessary in responding to the increasingly diverse racial and ethnic makeup of the United States' public school system and ensuring that teachers and students are navigating the educational experience in a way that both reflects this cultural change while also effecting social change.

\section{The Politics of Literacy Education}

In order to understand the necessity of critical literacy pedagogy, it is important to note that historically, there have been multiple perspectives to literacy theory and to whom and how literacy education should be presented (Young, 2010). Dating back to the slavery era and even after the Emancipation Proclamation, enslaved people, freed men and women, and free men and women sought out literacy education as a form of political power, given that citizens needed to 
be literate to participate in society (Enoch, 2008). Even as African-Americans slowly began to receive the rights to become literate and participate in politics, White discourse prevailed in teaching materials provided for rhetorical education (Enoch, 2008). To this day, AfricanAmerican students face obstacles of reconciling language and cultural differences caused by years of restricted access to literacy education. Perhaps not as racially explicit as constituting the illegality of literacy education to African-Americans and other people of color, oppression is more subtly transmitted through high-stakes standardized literacy testing, which demand the mastery of the language structure, conventions and vocabulary of the oppressor (Grant, 2004).

Although literacy education can often be framed as apolitical, historical precedent and present reality support otherwise. According to Hilary Janks, political ideologies can take root in curriculum and instruction, as "texts have social effects that are ... designed to recruit us into their version of 'the truth' and ... language can be used for both good and ill” (Janks et al., 2013, p. 5). What is taught and tested in the classroom upholds a certain discourse, whether implicitly or explicitly, which can affirm the social and political power of a certain culture. Thus, it is important to acknowledge language and literature as sociopolitical to challenge the power structures within the dominant discourses taught in schools, both in the past and present (Houchen, 2012). One must be fully aware of the perceptions of different ideologies presented in literature, as well as of languages and dialects, and develop a practice of questioning the rules of grammar created by the dominant culture (Janks, et al., 2013). However, to teach language in a way that is completely rid of linguistic prejudice in order to uproot dominant discourse may prove difficult, as its social power is sustained through strict teaching practices of Dominant American English grammar (Janks, et al., 2013; Grant, 2004). 


\section{Disrupting the Dominant Discourse of "Whiteness"}

Freire, Ladson-Billings, McLaren, Paris, and other pedagogues of critical pedagogy, culturally relevant pedagogy, and critical literacy share the mission of questioning the dominant culture within the education system. Within the historical context of racism and slavery in the United States, scholars of Critical Whiteness Studies and Critical Race Theory identify White culture as the dominant culture (Borsheim-Black, 2015). The term "Whiteness" is defined as an identity which benefits from emphasizing "the production and reproduction of dominance rather than subordination, normativity rather than marginality, and privilege rather than disadvantage" (Frankenberg, 1993, p. 410). In contrast to cultures of color, the concept of Whiteness is often assumed as "natural" and "normal" in negating that it is not "the Other" (marginalized cultures of color) (Chubbuck, 2004). Insofar as this is true within society, education as an institution can work to either sustain or disrupt the dominant culture as the only culture worth teaching and learning about. Teachers who do not take an activist approach ultimately contribute to the continuation of social power benefitting White culture and White students, thus failing to uplift marginalized students (Chubbuck, 2004). Thus, critical literacy, in its aim to raise consciousness and challenge the dominant discourses of texts taught in the English classroom, subsequently targets White supremacy and promotes a multicultural space for learning.

Because discourse is channeled through language, it holds the ability to create and shape knowledge about cultures, power structures, and institutions through literacy practices (Chubbuck, 2004). The aim of critical literacy is to eliminate inequalities by focusing on “discourse," defined as a "[system] of knowledge producing social and governmental 'technologies,' such as educational institutions and the media, which constitute power in society" (Lindsay, 2007, p. 427). The concept of reshaping literacy practices to reform discourse was 
recognized, but not theorized, by civil rights activists such as Malcolm X, who advocated for a “counter-hegemonic literacy" which would empower African-American culture and bring its literature to the canon as opposed to forcibly displacing "Other" cultural identities and discourses with the rhetoric of Whiteness (Miller, 2004). Such practices were met with resistance as they contained "deficit approaches" to literacy education, advocating for the advancement of a “monocultural and monolingual society" (Paris, 2012, p. 93). Supporters of this approach viewed languages of non-white cultures as deficient and sought to eradicate marginalized cultures by encouraging assimilation to the dominant culture. Thus, responding to the expected backlash towards disrupting the dominant culture of Whiteness, educational justice activists sought multicultural ways of teaching that would not only question dominant discourse, but do so in a way that fosters cultural integrity (Giroux, 1993).

\section{Towards Cultural Understanding, Not Cultural Assimilation}

Understanding "culture" and its effects within the classroom are key components to realizing the benefits and potential drawbacks of culturally relevant and critical literacy pedagogical practices. "Culture" is defined as the "values, traditions, and beliefs that influence the behavior of social groups" (Parsons, 2003, p. 23). Within the classroom, a student's cultural identity often guides how he or she learns as different cultures hold a variety of social assumptions and world views towards how and what one learns (Parsons, 2003). In order to reconcile cultural identities, students and teachers who are exposed to such diversity must challenge their own presumptions about society in order to be open to true cultural understanding.

Unlike the assimilationist approach to teaching marginalized students, which contends that one's students fit conform to the guidelines of mainstream culture, culturally relevant and 
critical literacy pedagogies are defined as "pedagogies of opposition" (Ladson-Billings, 1992; Giroux, 1993). Instead of maintaining the status-quo while teaching, critical literacy pedagogues both challenge the beliefs of the dominant culture and celebrate the diverse cultures of one's students in a way that empowers all, but specifically those marginalized groups. Critical literacy contends that students should feel engaged as active citizens and promote social change through dialogue. It is important to note that these pedagogies of opposition do not completely reject the dominant culture, but simply that they do not ask marginalized cultures to conform to such practices. This method of teaching can prove difficult, as students are pushed to reach a level of cognition that requires a nonconformist approach and a critical examination of the structures of social power present within literacy education and society as a whole (Ladson-Billings, 1992). However, the skills to practice critical literacy pedagogy can take several forms within English Language Arts classrooms across the globe, and teachers and students can all challenge choices in literacies, as well as acknowledge the power dynamics that exist within language (Perry, 1993). Although the mission of informing a critical literacy classroom is of value in ensuring that students are taught the knowledge and skills necessary for transferring power from the dominant to marginalized cultures, there still exist cultural, social, and political obstacles to achieving this goal, such as the dominant discourse of "Whiteness," racial colorblindness, "deficit views" of languages aside from Dominant American English, and high-stakes testing which perpetuates oppressive language norms (Winn, et al., 2011).

\section{Curbing Critical Literacy Pedagogy by Valuing High-Stakes Testing}

In recognizing the discrepancies in literacy rates between racial groups, the United States federal government passed the No Child Left Behind (NCLB) policy in 2002, which sought to create national standards to close the "achievement gap" that existed between White students and 
students of color (African-Americans, Latino/a, Asian, and Indigenous Americans) (Grant, 2004). Although proposed with an "anti-racist" agenda, NCLB inevitably increased the achievement gap between different racial groups by mandating that teachers and students meet the standards of language established by the dominant culture (Grant, 2004). Consequently, education became increasingly political, as private corporations were now given the opportunity to hold a stake in what should be covered in the K-12 curriculum and increase their political and economic power by profiting from the testing industry. Viewing education as a business has especially harmed marginalized groups, such as African-American students, who were previously disadvantaged from receiving literacy education. Instead of ensuring that public education accommodate the differentiated learning strategies and levels of all students, many in the United States began to reward those who were "highly educated" in accordance with the established testing standards, and punish students who had minimal education (Grant, 2004). The emphasis on standards-based learning was caused by the growing importance of achieving on standardized tests, as doing so allowed benefits, such as access to higher education (Grant, 2004).

Thus, high-stakes, standardized tests became the guide in which most public school teachers navigated their curriculum, wanting to ensure that their students gain the skills necessary to pass these tests. By tying school achievement to economic and political benefits, such as a school's funding from the state and/or federal government, high-stakes testing restricted both teachers and students from teaching and learning "real-life lessons" that reflect a commitment to the aims of critical literacy (Grant, 2004). Instead of openly addressing cultural biases and systemic racial inequality within literacy education, English teachers often relay the dominant discourse by "teaching to the test," which privileges the dominant culture (Grant, 
2004). The negative consequences affecting students of color can be viewed through the problematic standards-based learning supported by the system, which assesses an understanding of Dominant American English and thus eliminates space for diverse dialects of English (Delpit, 1986). In turn, critical literacy pedagogues are affected by the lack of freedom offered in curriculum choices and may not be able to successfully foster cultural understanding and critical consciousness encouraged by educational justice activists.

Although there are cases in which outstanding teachers have been able to navigate the complexities of teaching and testing in order to offer their diverse students a socially just education alongside the "necessary skills" for test-taking, these leaders cannot singlehandedly eradicate the oppressive testing structure that prioritizes a traditional approach to teaching literacy over critical literacy instruction. While strong culturally relevant and critical literacy pedagogues are needed to create social change and promote racial equality within education, it is important to note that these same teachers may still experience the pressures of an educational system that emphasizes Dominant American English grammar instruction and reinforces the dominant discourse of Whiteness, rather than disrupting it (Borsheim-Black, 2015).

\section{Acknowledging Teacher Identity and School/Community Environment}

It may be argued that high-stakes testing alone cannot be the sole cause of racial inequality in the education system and the primary obstacle to practicing critical literacy pedagogy, as there exist multiple barriers in other case studies, such as when a teacher's racial and ethnic identity is dissimilar to his or her own students, or when there is skepticism within the school and/or community towards implementing critical literary pedagogy. In a study conducted by Borsheim-Black, Ms. Allen, a White female, faced difficulties in complete identification with 
her students as she expressed concern over whether she might "inadvertently reinforce White privilege and supremacy despite her goals to do the opposite" (Borsheim-Black, 2015; p. 412). This concern is shared by teachers in similar case studies, who express discomfort in mentioning race, advocate for a "colorblind" view of race, and excuse White students' lack of diverse experiences in predominantly White classrooms to validate apathy towards social justice (Borsheim-Black, 2015; Young, 2010). This lack of critical consciousness fails to meet the expectations of critical pedagogy advocates (Giroux, 1993). If a teacher is not conscious of his or her own cultural identity, with the understanding that identity in itself is continuously evolving, students are unable to benefit from not only affirming their own cultural identities, but potentially embracing other diverse identities shared in the classroom.

\section{Critical Literacy Pedagogy at Riverdale High School (Case Study)}

Because critical literacy involves a diversity of teaching strategies and curriculum choices depending on the classroom, I found it necessary to conduct my own study of the pedagogy in practice and examine any obstacles presented to the students' learning of social change ideals. The teacher I chose to observe identifies as a White male and Louisville native. Mr. Walker's $11^{\text {th }}$ grade English Language Arts classroom was recommended by a teacher who identified with critical literacy pedagogy, but no longer taught in the English classroom setting. Mr. Walker holds a Bachelor's Degree in Education from the University of Louisville and a Master's Degree in Education from Bellarmine University. At the time of the study, Mr. Walker was in his seventh year of teaching English Language Arts at Riverdale High School. Although Mr. Walker was unfamiliar with the term "critical literacy," his perspective towards literacy education shared characteristics with the pedagogy, such as the stated needs for, as he called it, 
"critical thinking within literature" and "thinking outside of being White" in order to teach his diverse students (Field notes, Period 1, October 31, 2016).

\section{Methods}

The primary goal of this study was to understand how critical literacy pedagogy is generally used in a K-12 English classroom and to describe any limitations in reaching the following objectives of critical literacy: encouraging active citizenry through engagement with various texts, disrupting dominant discourse and dismantling English language power structures, and promoting an understanding of cultural identity to create a multicultural learning environment. To achieve this goal, the study utilized qualitative research methods such as interacting as a participant-observer and taking field notes for more than 150 hours in the classroom, conducting interviews with both the teacher and students, and analyzing student writing samples and other class materials that may have been used to guide the teacher's and students' learning experience. Two class periods were observed and utilized in this case study, with an overall total of 47 students. All student participants were from diverse racial, ethnic, and socioeconomic backgrounds, most of which do not align with the teacher's White, male, and upper-middle class background. As the teacher taught with traits of critical literacy pedagogy and designed curriculum to question dominant discourse, and the demographics of the students across two class periods reflected an underrepresented community in Louisville, Mr. Walker's classes seemed fit to answer the main research question: How does a teacher invested in Critical Literacy negotiate the pressures of high-stakes testing?

\section{School and Course Context}

Participants attended Riverdale High School, located in District 5 of Jefferson County Public Schools. In August 2016, there were 1,284 students enrolled (grades 9-12). The racial 
makeup of Riverdale High School is composed of 52\% African-American students, 25\% White students, 12\% Latinx American students, and 11\% of other racial categories ("JCPS 2015-2016 Current Enrollment by Race and Gender," 2015). Most of the students are located within the geographic range of Riverdale High School, with about $70.6 \%$ of students living within the two surrounding zip codes of the area, which hold median household incomes ranging from \$26,888.00 to \$38,213.00 (“JCPS 2015-2016 Median Household Income by ZIP Code Map,” 2015). In addition, $81.7 \%$ of students enrolled at Riverdale High School are eligible for free/reduced lunch (“JCPS 2015-2016 Free/Reduced Lunch Participation,” 2015).

In this study, participants were enrolled in the $11^{\text {th }}$ grade English Language Arts course, labeled as "ENGLISH III." This course was taught by two teachers at Riverdale High School, with Mr. Walker being responsible for five class periods each day. Data was collected from the end of October to the end of January. English III students were expected to meet in class Monday through Friday, for approximately 50 minutes each class period. The participants observed were from class periods 1 and 2, both of which were taught by Mr. Walker.

As mandated by Jefferson County Public Schools, the objectives of the English III course were to prepare high school juniors to "explore their options beyond high school and what will be expected of them" ("English/Language Arts Curriculum," 2017). The core curriculum of the course is guided by 'essential questions' that prompt students to "better understand the big ideas in a course; that is, the ideas they would explore and grapple with through discussions, written responses, and ongoing investigations and research — all of which might culminate in a paper, a presentation, or some other appropriate project or artifact" ("English/Language Arts Curriculum," 2017). English Language Arts teachers are also encouraged to "help students consider their futures and how they will participate as citizens of the world" ("English/Language 
Arts Curriculum," 2017). All $11^{\text {th }}$ grade students are required to complete the ACT college preparation exam in March and the On-Demand writing assessment in April ("English/Language Arts Curriculum," 2017).

\section{Participants}

In this case study, I utilized purposive sampling as the primary strategy for gathering data from the instructor participant. While working as a substitute teacher for Jefferson County Public Schools, I substituted for Mr. Walker's $11^{\text {th }}$ grade English Language Arts class in May 2016, as Mr. Walker proctored the English III End-of-Course exam. Upon surveying Mr. Walker's classroom, I found a book propped on the bookshelf, Case Studies on Diversity and Social Justice Education by Paul C. Gorski and Seema G. Pothini. Assuming Mr. Walker utilized this text to guide his instruction, when I met him, I asked him questions about the educational resource which I found useful to my study of critical literacy and effecting social change in education. Mr. Walker shared information about the necessity of such a resource with the diverse racial demographics of his classes, and offered me the book to help with my endeavors as an educator. Keeping in contact with Mr. Walker into the fall semester of 2016, I identified him as one of three potential instructors for the case study. In expanding my research participant choices, I reached out to professors within the College of Education and English Department about teachers in Jefferson County who might align with critical literacy pedagogy or another social justice oriented teaching practice. Coincidentally, I was referred to Mr. Walker's mentor teacher, who informed me that she was no longer teaching in a classroom setting at Riverdale High School, but recommended Mr. Walker as a fitting instructor participant for the focus of the study. Thus, I scheduled a shadow visit before conducting official observations in order to ensure the potential in participation from Mr. Walker and his students. Although Mr. Walker did not use 
the phrase "critical literacy," to describe his pedagogy, as outlined above, his teaching style aligned with the characteristics found in literature discussing the social change and cultural consciousness aims of the pedagogy.

The students quoted in this case study and those chosen for in-depth audio interviews were selected by a strategy of random sampling. Some students showcased active participation in daily class activities, while others reflected a lack of participation. All students who participated in class conversations and discussion with Mr. Walker were asked for Subject Assent/Parent or Guardian Consent to take part in the study, which included permission to utilize quotes and soundbites from audio recordings of class observations and out-of-class interviews. The privacy of the teacher and students is kept throughout the paper through use of pseudonyms.

Table 1. Students Quoted and/or Interviewed Identified by Ethnicity, Gender, and Grade Level (Listed in order of appearance in case study, *students interviewed)

\begin{tabular}{|l|l|l|l|l|}
\hline & Pseudonym & Ethnicity & Gender & Grade Level \\
\hline 1 & Marcus & African-American & Male & Junior \\
\hline $2^{*}$ & Nia & African-American & Female & Junior \\
\hline 3 & Angelo & African-American & Male & Junior \\
\hline $4^{*}$ & Jamila & African-American & Female & Junior \\
\hline $5^{*}$ & Kody & African-American & Male & Junior \\
\hline 6 & Demetria & African-American & Female & Junior \\
\hline $7^{*}$ & Zoe & African-American & Female & Junior \\
\hline 8 & Kevin & African-American & Male & Junior \\
\hline 9 & Cyrus & Biracial & Male & Junior \\
\hline 10 & Serena & African-American & Female & Junior \\
\hline
\end{tabular}




\begin{tabular}{|l|l|l|l|l|}
\hline $11^{*}$ & Jonathan & Biracial & Male & Junior \\
\hline $12^{*}$ & Jordan & African-American & Male & Junior \\
\hline 13 & Brandon & African-American & Male & Junior \\
\hline $14^{*}$ & Sadi & African-American & Female & Junior \\
\hline 15 & Michael & White & Male & Junior \\
\hline $16^{*}$ & David & Biracial & Male & Junior \\
\hline 17 & Antonia & African-American & Female & Junior \\
\hline $18^{*}$ & Mariah & Multiracial & Female & Junior \\
\hline 19 & Shakira & African-American & Female & Junior \\
\hline $20^{*}$ & Daniel & White & Male & Junior \\
\hline
\end{tabular}

\section{Data Sources}

The primary sources of data collecting for this study are ethnographic field notes, audio recordings of interviews, writing samples, and supplemental handouts from daily lessons, As a researcher, I took extensive field notes from late October 2016 to late January 2017, with over 150 hours of classroom observation within 45 days. Field notes were collected in the $1^{\text {st }}$ and $2^{\text {nd }}$ class periods of each day, which captured teacher behavior, attitude, and curriculum choices and student reactions to the teacher, curriculum, and overall learning experience. In addition, I outlined detailed descriptions of the intended lesson plan as explicitly written on the mandatory "Riverdale High School: Objectives" posters displayed on the front bulletin board of the classroom, instructions written on the dry-erase board or given on supplemental material. The observational field notes also included direct quotes from participating students, which include 
interactions between student and student, student and teacher, student and researcher, and teacher and researcher.

When interviewing participants, I asked questions which concerned teacher/student behavior, classroom culture, and aspects of critical literacy. All interviews with students were conducted outside of the classroom to ensure the privacy of students' responses. Interview questions for the students were framed to capture student responses to academic background, school culture, and the effects of aspects of critical literacy pedagogy on his or her learning experiences (Appendix A). Specific interview questions for the teacher were framed to capture teaching strategies and intentions, as well as felt obstacles or difficulties in implementing critical literacy pedagogy in the classroom (Appendix B).

Audio recordings were utilized only during out-of-class individual interviews. This was a personal decision made based on recommendations by the JCPS Data Management, Planning, and Program Evaluation Center. ${ }^{3}$ and the potential to shift the atmosphere of the whole-class discussion. The recording equipment consisted of a smart phone device and built-in microphone. I conducted eleven interviews total, with the ten focal students and the instructor. Each interview lasted between fifteen to thirty minutes long, with about 198 minutes of recording total.

\section{Data Analysis}

When coding the data collected from both class periods, I re-read and typed my field notes, as well as transcribed all interviews of the participants. During my daily observations, I consistently wrote analytical memos within my field notes about critical literacy strategies, grammar instruction activities, and the teacher's and students' positive/negative interactions with

\footnotetext{
${ }^{3}$ JCPS required that "any student on the audio or video must have a consent/assent form on file from both the student and parent." However, in my IRB forms, students and parents/guardians could only decline participation by not completing a form.
} 
either pedagogy, which assisted in coding. Within my findings, I identified themes similar to those found in critical literacy research, such as critical consciousness and cultural competence. Further along in my study, I coded for external pressures which presented obstacles to the critical literacy experience, such as high-stakes testing and grammar instruction.

\section{Role as a Researcher}

As the researcher leading the study, I planned to adopt a role as an attentive, yet unhelpful, observer of the classroom. In doing so, I hoped to allow the participants to engage with one another naturally. Mr. Walker agreed with my role as observer, and did not ask for classroom assistance that might influence the students' interactions with the research study. Within a week of my study, however, my role evolved from that of observer to being a participant observer. Instead of holding a detached position, I became more comfortable and active in my researcher role and conducted daily walkthroughs of the classroom, checking in with students, closely observing students' work, and initiating discussion with students to follow up on comments made during lessons or written on assignments. In addition, I began attending to students who asked for my help or clarification on daily work and was looked to as a consistent source of assistance when Mr. Walker was working with another student. While acting as a participant observer, I took extensive notes on student discussion with one another, the teacher, and myself.

\section{Findings}

The sections below share the observations made from the case study conducted in Mr. Walker's English III classes (periods 1 and 2) over the course of 8 weeks. The case study analyzes teacher behavior, actions, and curriculum choices, as well as the learning experiences of students within the framework of critical literacy pedagogy, such as developing cultural 
competence and a critical consciousness through literature. The first section describes how Mr. Walker implemented critical literacy pedagogy by addressing the politicization of literacy education, disrupting the dominant discourse of Whiteness, and fostering cultural understanding instead of assimilation. The second section presents the observed obstacles to meeting the aims of critical literacy pedagogy, identifying an increased focus on grammar instruction due to the external pressures of high-stakes testing.

\section{The Politics of Literacy Education}

Mr. Walker employed a number of strategies discussed by culturally relevant pedagogy and critical literacy theorists, such as choosing diverse literature, providing supplemental reading material to give social context to literature, reading from a standpoint of "resistance" to disrupt Whiteness, engaging in discussions to prompt critical thinking, and measuring student progress through creative projects and assessments. Guided by the JCPS Curriculum map, Mr. Walker was given a list of district-approved books for English III at the beginning of the 2016-17 school year to assist in preparing lesson plans for each unit. When beginning Unit 2, Mr. Walker was offered three literary choices: Lorraine Hansberry's A Raisin in the Sun, Jon Krakauer's Into the Wild, and Zora Neale Hurston's Their Eyes Were Watching God. Mr. Walker chose to focus his unit on the play, A Raisin in the Sun, which brought attention to housing discrimination during the Civil Rights era. The students began reading A Raisin in the Sun on October 24, 2016, and completed the unit on December 9, 2016.

On my first day of observation, October 31, 2016, I asked Mr. Walker why he chose Hansberry's play, to which he responded that his students had just completed an extensive study of F. Scott Fitzgerald's The Great Gatsby and he feared exposing his diverse students to solely 
literature written by White authors, which prompted the potential for African-American culture to be excluded entirely from "American history as a whole" (FN, P. 1, 10/31/16) ${ }^{4}$. In this conversation, I inquired about Mr. Walker's motives further, asking about the difference in teaching The Great Gatsby and A Raisin in the Sun. Mr. Walker lacked obvious excitement for The Great Gatsby, expressing that "The unit went fine" and that the beginning of the semester often served as a "warm-up" period, in which the teacher and students are just beginning to get to know one another's teaching style and learning abilities (FN, P.1, 10/31/16). Referring back to the topic of choosing A Raisin in the Sun, Mr. Walker noted the lack of African-American representation in The Great Gatsby, both in the book and movie. Mr. Walker recognized a need to teach his students varied perspectives of history, which included literary and visual representation of marginalized groups, in order to promote civic engagement (FN, P. 1, 10/31/16). If the opportunity was missed, "they [students] would be incapable of being active citizens or functioning members of the community" (FN, P. 1, 10/31/16). This belief in the power of literacy education, paired with questioning the lack of cultural representation in the discourse taught in schools, showed a natural understanding of critical literacy pedagogy. Throughout the course of the case study, Mr. Walker utilized a number of critical literacy-guided strategies to disrupt dominant discourse and develop students' cultural understanding to effect social change.

\section{Disrupting Dominant Discourse}

My daily observations included paying close attention to strategies of critical literacy pedagogy and the expectation of challenging the dominant discourse of Whiteness. To prepare

\footnotetext{
${ }^{4}$ FN, P. 1, 10/31/16: Field notes, Period 1, October 31, 2016.
} 
for Unit 2, Mr. Walker explained the social and historical context of Lorraine Hansberry's $A$ Raisin in the Sun, which paved the path for critical literacy practices that would be utilized in the classroom throughout the semester. Because Unit 2 began one week before my first observation, Mr. Walker informed me of the previous lessons covered. On October 24, 2016, the first day of Unit 2, Mr. Walker explained the background of Hansberry, indicating that she was the first African-American woman playwright to premiere a play on Broadway, A Raisin in the Sun (FN, P. 1, 10/31/16). The play, as explained by Mr. Walker, was written to shed light on issues of racism and housing discrimination during the time period. To give his students a better understanding of how those themes operated today, Mr. Walker provided supplemental material: a 2014 article written in The New York Times, "Discrimination in Housing Against Nonwhites Persists Quietly," by Susan Chenelle and Audrey Fisch (FN, P. 1, 10/31/16). The students were asked to compare and contrast housing discrimination from the Civil Rights Era and present-day, using a "Document Analysis" worksheet attached to the article, which listed the following questions to promote critical thinking: "Who created this document? Who is the intended audience? How does the creator of this document get his or her message or ideas across? How would you describe the language and tone of the document? Why do you think the document was originally created? Why do you think many consider it important?” (FN, P. 1, 10/31/16). Mr. Walker's historical context extended the opportunity for students to question the text and disrupt dominant discourse.

On my first day of observation on October 31, students were asked to prepare a thesis statement and collect data comparing historical and present forms of racism and housing discrimination (See Appendix C for instructions). Students were to refer to the NYT article, supplemental worksheet, and A Raisin in the Sun to engage in prewriting as part of a practice On- 
Demand writing assessment. Upon my first impression of the classroom, throughout the working period in both classes, Mr. Walker checked in on students' progress and answered any questions about using specific examples from A Raisin in the Sun. Based on my observations, students had most difficulty with finding quotes which displayed traces of racism within housing discrimination, as Angelo asked, "Was Lindner racist?" referring to the White male character who adamantly discouraged an African-American family (the Younger family) from moving into their desired home in a predominantly White neighborhood (FN, P. 1, 10/31/16). Mr. Walker thus explained to Angelo the political motive behind Lindner's passive aggressive words, "He told the family to move because he was racist. Just because he's not calling them names doesn't mean he isn't racist. He talks about the discomfort of living with 'different' people” (FN, P. 1, 10/31/16).

The following day, realizing that much of the class seemed to be confused about the lack of explicit racial statements, Mr. Walker opened the lesson by discussing the difference between "implicit" and "explicit bias" (FN, P. 1, 11/1/16). Mr. Walked mentioned to students that when attempting to find quotes in the play, that traces of racism may not be as "blatant" in their words and actions, stating that "people may not be explicit in their racial bias, such as not calling black people the 'n-word,' [but] there are subtle actions that indicate a bias, or prejudice, in one's treatment toward one another" (FN, P. 1, 11/1/16). Some students, such as Jamila, still showed confusion after hearing Mr. Walker's explanation: "So, what you're saying is people are still racist, but we can't tell?" (FN, P. 2, 11/1/16). Another student, Kody, responded, "Well, I mean you can still tell, but they just might not say anything to your face" (FN, P. 2, 11/1/16). Mr. Walker clarified his differentiation, "When someone holds implicit bias, that person may or may not realize what they are saying or how they are acting towards someone else. In an explicit 
manner, people are aware of what they are saying and doing. However, both cases of racial bias are harmful" (FN, P. 2, 11/1/16). After Mr. Walker's brief discussion, I chose to do my own walkthrough of the classroom to gauge the students' understanding of the terms. One student, Demetria, explained implicit racism in her own words: "He [Lindner] tried to sugar coat what he was saying by saying 'I don't say we are perfect and there is a lot of wrong in some of the things they want. But you've got to admit that a man, right or wrong, has the right to want to have the neighborhood he lives in a certain kind of way"' (FN, P. 2, 11/1/16).

In later observations, Mr. Walker sustained his attention to connecting literature to modern issues outside of the classroom. As a mid-unit assessment of students' understanding of the play, Mr. Walker introduced a Langston Hughes-inspired poetry project which focused on the poem "A Dream Deferred," the inspiration for Lorraine Hansberry's naming of the play, $A$ Raisin in the Sun (FN, P. 1, 11/16/16). Upon introducing the creative assessment to gauge students' understanding of the play, Mr. Walker provided presentation printouts and a discussion packet that listed the following questions: "What are some civil rights movements of the past? Are there any civil rights movements still going on today? What are they? Did any of these groups win their civil rights instantly? Why would a government defer someone's rights?" (FN, P. 1, 11/16/16). During class discussion, students immediately referred to the Black Lives Matter (BLM) and All Lives Matter movements, with Zoe explaining that BLM initiated because "They keep killin' us" (FN, P. 2, 11/16/16). Another student, Kevin, chimed in to acknowledge the objective of Black Lives Matter in contrast to All Lives Matter, "Well, everyone’s lives do matter, but right now people need to pay attention to Black lives" (FN, P. 2, 11/16/16). Although the students did not mention the names of past movements, Mr. Walker provided information on the Women's Suffrage Movement and Civil Rights Movement in his presentation, and discussed 
the passage of the Fair Housing Act in 1968 to give context to the housing discrimination in $A$ Raisin in the Sun (FN, P. 1, 11/16/16).

The acknowledgment of past and present forms of discrimination, as well as implicit and explicit racial bias in words and actions, served as prime examples in disrupting dominant discourse concerning racism today. Instead of avoiding the students' point of confusion surrounding racism within the housing sector, Mr. Walker confronted the issue by engaging in discussion that would teach his students to identify implicit bias presented within discourse that may seem neutral at face. Throughout the discussions of race, Mr. Walker did not shy away from pointing out Lindner's racial identity as a White male or the Younger family's African-American racial background. In addition, the discussion of modern movements, such as Black Lives Matter versus All Lives Matter, shows a challenge in the dominant discourse from the predominantly White-centered discussion in support of “All Lives Matter.” Although Mr. Walker did not noticeably choose a side in discussing either movement, his support of the ongoing discussion, which naturally disrupted Whiteness, showed his comfort, as well as his students,' in challenging the dominant discourse. From my interpretation of the lessons learned from the healthy discussions which occurred during observations of Unit 2, the emphasis on racism and racial identity showed Mr. Walker's understanding of the privilege of his own Whiteness, alongside his acknowledgment of Hansberry's intention to disrupt the dominant discourse that displayed obvious traces of implicit bias. The actions and behavior of Mr. Walker showed a clear understanding of the mission of critical literacy pedagogy to engage with the dominant discourse through reading and writing exercises. 


\section{Developing Cultural Understanding}

One of the defining components of critical literacy pedagogy is that of maintaining the use of diverse languages in order to develop greater cultural understanding between students and the teacher. Perhaps the most evident showcasing of cultural understanding was Mr. Walker's flexible use of language within the classroom. On my first day of observing on October 31, I noticed that Mr. Walker naturally spoke similarly to the students he was conversing with. At the end of first period, Angelo asked Mr. Walker, “We don't get no candy for Halloween?" To which Mr. Walker responded, 'I've tried giving candy out in past years. If I give y'all candy, y'all will just say it's nasty and throw it out" (FN, P. 1, 10/31/16). The student laughed at Mr. Walker's imitation of the tone that most students in the class used to express the phrase, "it's nasty," and showed respect to Mr. Walker's decision by choosing not to comment further (FN, P. $1,10 / 31 / 16)$

In addition to not strictly enforcing the use of Dominant American English, Mr. Walker taught a journalism elective, responsible for publishing the weekly Riverdale High School newsletter, which showed his interest in student voice and language. The newsletter featured editorials and news articles written by students, covering school, local, and national news, as well as opinions on politics, music, and more. Showing Mr. Walker's understanding of language customs in the school culture further, he published the "Riverdale High School Urban Dictionary (A Reference Guide for Teachers)" in the November 4, 2016 issue. In this guide, Mr. Walker included entries of common words used by students:

Stuntin' - Also known as flexing; exaggerating or lying, e.g. "I ain't stuntin"” or "I ain't even gonna flex." 
Kilt - Similar to hit or smacked; to be extremely unattractive or to behave in an ugly manner $(\mathrm{FN}, 11 / 4 / 16)$

When asked what inspired him to write the resource, he responded, "Sometimes it can be difficult to understand our students. We have to make that effort ourselves" (FN, 11/4/16). The inclusion of slang showed the teacher's basic understanding of language as a form of power, as Mr. Walker did not explicitly ask students to rid of the language customs of their culture within class discussion.

Although Mr. Walker ensured the development of cultural understanding through language with his students, he did not discuss the matter extensively. In a lesson towards the end of November, however, Mr. Walker took the opportunity to discuss the concept of "cultural assimilation" in A Raisin in the Sun (FN, P. 1, 11/28/16). Mr. Walker asked his students to respond to the open-response prompt: “Define 'assimilation.' How does assimilation affect people? How does the idea of assimilation become significant (important) to characters within $A$ Raisin in the Sun?" (FN, P. 1, 11/28/16). Some students, such as Nia, found it difficult to define 'assimilation,' asking Mr. Walker to provide a specific example of the term. Opening up the discussion to the class, Mr. Walker explained, "When someone moves to the United States from another country, they might assimilate to American culture by adjusting to customs, wearing Western-style clothing, or listening to American music" (FN, P. 1, 11/28/16). Angelo asked a follow-up question, “Does assimilation mean to conform?” To which Mr. Walker responded by breaking down the word 'conform,' the terms can be used similarly: "To 'form' is to create something, to shape something. The prefix 'con' means 'with.' To 'conform,' then, is to be 'shaped with"” (FN, P. 1, 11/28/16). 
Further in this discussion, Mr. Walker explained that A Raisin in the Sun explored both perspectives of cultural assimilation and celebration within the African-American community. To draw upon an example of rejecting assimilation, Mr. Walker showed a YouTube video of the scene in which Beneatha wears a colorful dashiki, traditional Nigerian clothing, and a matching headdress (FN, P. 1, 11/28/16). The students then discussed why Beneatha wore the outfit, making comments such as "African pride," "being proud of her heritage" or "showing that she wants to stand out" (FN, P. 1, 11/28/16). Offering an opposing viewpoint, Kody referred to the quote in which Walter is attempting to discuss business with George, but is instead frustrated with his appearance of assimilation instead: "I know ain't nothing in this world as busy as you colored college boys with your fraternity pins and white shoes..." (FN, P. 2, 11/28/16). Another student, Cyrus, offered a personal experience of encountering cultural assimilation in his ideas for writing, sharing his story in which he held onto his 'country accent' when he moved from Atlanta to Louisville as a child, but eventually "assimilated to the way they talked in Louisville" (FN, P. 2, 11/28/16). Although the students did not explicitly mention the power structure that exists behind the privileged "norms" of society, whether by appearance or aspects of language, there showed an evident understanding of identifying and respecting differences in culture.

The exchanges between Mr. Walker and his students with mixed use of Dominant American English and African-American Language emphasized an important concept of critical literacy in embracing multiple literacies. Instead of seeming out of place for using a varied dialect of English, Mr. Walker seemed to carry greater respect from his students for accepting the various ways in which they spoke, as opposing to asking students to speak in what $\mathrm{Mr}$. Walker identified as "Standard American English." Additionally, Mr. Walker took a position of rejection to cultural assimilation in class discussions, which affirms his practice of not only 
disrupting dominant discourse, but developing cultural understanding by embracing diverse customs. To properly gauge Mr. Walker's cultural understanding within the classroom, during my interviews, I asked students of their general thoughts of Mr. Walker as a teacher. Nia stated her support of Mr. Walker's treatment of different cultures within the classroom, 'He don't treat us any different. That's what I like about him" (Interview, January 20, 2017). When Jordan was interviewed, he related Mr. Walker's relatable character to language: "Mr. Walker is like the cool teacher. He tries to act like he's one of us, like talk like us and stuff' (Interview, 1/20/17). Thus, Mr. Walker could be viewed as meeting the standard of developing cultural understanding through language, as is noted by critical literacy pedagogues. Throughout most of Unit 2, Mr. Walker showed considerable promise in both challenging the dominant discourse and developing cultural understanding through his use of various critical literacy methods. However, towards the end of the semester and into January 2017, I observed an inconsistency in Mr. Walker's inclusion of African-American Language in the classroom, as students were penalized for not writing within the structures of Standard American English for On-Demand writing practice assessments.

\section{The Pressures of High-Stakes Testing on Critical Literacy Pedagogy}

As the study progressed throughout the months of November, December, and January, I observed several shifts in Mr. Walker's pedagogical practices, gradually switching from obvious aspects of critical literacy to a pedagogy of grammar instruction. Although acknowledging the need for cultural consciousness and critical thinking as goals to be met through reading, writing, and discussion activities, Mr. Walker also held $11^{\text {th }}$ grade students accountable to the pressures of both the On-Demand writing assessment and ACT exam. The freewriting exercises, 
encouraged by critical literacy pedagogues, allowed the teacher and students to engage in practices to potentially effect social change, but did not assist in "student achievement" as measured by assessment standards. After grading the first practice On-Demand writing assessment on November 4 , he found that only 4 out of 47 students sampled scored a 3 or above on the On-Demand writing scale (out of 4 points total). Points were deducted from most students' assessments because of missed grammar conventions, issues of sentence structure, and the overall organization of the essay (FN, P. 1, 11/9/16). Thus, Mr. Walker began implementing "pop-up lessons" of grammar instruction to serve as warm-up exercises (or, as is presented further in the study, full-day lessons) in addition to, or in place of, critical literacy approaches used in analyzing literature (re: prewriting or journal-based exit-slips; discussions surrounding sociopolitical topics; creative poetry project to assess student understanding).

Although lessons of grammar instruction were not entirely new to Mr. Walker's Unit 2, as two warm-up exercises were used as opportunities to review "basics of English" within the first week of my observations, the focus on grammar instruction heavily increased after Mr. Walker returned the graded On-Demand writing practice assessments to students (FN, P. 1, 11/4/16; FN, P. 1, 11/10/16). Such lessons during Unit 2 included review of subjects and predicates, independent/dependent clauses, compound/complex sentences, simple/compound sentences, and paragraph transitions (FANBOYS: For, And, Nor, But, Or, Yet, So), in order to improve writing for the On-Demand assessment. The standards used for scoring the On-Demand writing assessment are as follows:

_/4 The essay clearly addresses and focuses exclusively on the prompt. _ 14 The essay contains clearly cited evidence in each body paragraph.

_ 14 The essay has a completed introductory body paragraph with a clearly stated thesis. _ 14 The essay contains explanations of each piece of evidence. 
_/4 The essay is relatively free of sentence and grammar errors (the mistakes do not distract from the essay's purpose or meaning).

_ 14 The essay uses appropriate and relevant evidence from provided resources.

14 The essay is complete, with an introduction, body paragraphs, and conclusion.

/4 The essay conducts an authentic and deep analysis of the prompt and resources.

(FN, P. 1, 11/9/16)

Although some students, such as Serena, showed great promise in ideas surrounding the themes of racism and housing discrimination in A Raisin in the Sun, as she was commended for her analysis and findings of evidence within the play, her articulation through writing was marked for grammatical errors and faulty organization, as she scored $2 / 4$ in three standards (clearly stated thesis, sentence and grammar errors, completion of essay) (FN, P. 2, 11/9/16). When receiving back the graded On-Demand writing assessments, there were multiple expressions of disdain concerning the "red markings" on their papers and low grades, with students, such as Angelo and Jonathan, asking Mr. Walker for opportunities of extra-credit (FN, P. 2, 11/9/16).

Towards the end of Unit 2, students were once more challenged with reconciling Standard American English grammar and the aims of critical literacy to showcase an understanding of Lorraine Hansberry's themes of disrupting the norms of White society and addressing racism within the housing sector. The students were asked to read Langston Hughes' "A Dream Deferred," and model Hughes' poetic style in creating a poem that showcased one's personal dream being deferred (See project instructions and “A Dream Deferred” in Appendix D) (FN, P. 1, 11/22/16). Mr. Walker previously chose not to create a rubric to judge the poems, but found difficulty in students' misunderstanding of project guidelines. On the project prewriting worksheet, Mr. Walker asked the students to "list verbs, nouns, and adjectives" to assist 
in formulating their poems. One student ${ }^{5}$ listed his verbs as "dead, jail," nouns as "casket, dark, sad, gloomy," and adjectives as "cold, pale." In addition to a confusion of parts of speech in writing, I observed that most students did not follow the instructions in imitating Hughes' poetic structure as was outlined in the creative project guidelines.

A poem written by an African-American male student showed a loose verse structure: "What happen to the shot you take/ Do you hit or do you miss/ But you miss every shot you I take in life/ We all take a shot/ Will it make or miss" (FN, P. 1, 11/22/16). Another student showed an understanding of rhyme scheme, but veered from the structure expected: "What happens to a dream deferred?/ Fourth word has occurred, Horn poet by me/ No money Not funny, Had Humor Late bloomer./ Did suggest go west/ Gain vote Grab coat/ Is Hillary A distillery/ Big loss is cross/ Started raining quit complaining" (FN, P. 2, 11/22/16). On the other hand, some students, such as an African-American female student, showed an understanding of disrupting dominant discourse despite not following the guidelines of the project: "What happens when you make white people uncomfortable?/ -is it because I'm foreign?/ -or is it because im a muslim? -is it because I'm black?/ -or is it the way I dress?/ -maybe it is a good thing?/ -or does it go sideways?" (FN, P. 2, 11/22/16). Towards the end of the week, most students turned in poems that related to personal experiences, but lacked the poetic structure of Hughes (FN, P. 2, 11/22/16). Mr. Walker accepted all projects and chose to decorate the classroom and hallway with the poems to showcase their work, but following the end of the project, Mr. Walker spent multiple days discussing basics of grammar in order "to help students better organize their

${ }^{5}$ Given that quotes from students' writing may make the students identifiable, pseudonyms are not used in this section to protect the anonymity of students who are quoted in other section of this thesis. This is done to honor the JCPS recommendation that "precautions should be taken to ensure anonymity of students, such as no identifying characteristics of students, or groups of students, should be given that may lead to the identification of individual students in the report." 
writing" for the final On-Demand writing assessment the students would complete at the end of the term (FN, P. 1, 11/28/16).

Given Mr. Walker's frustration with students' lack of knowledge of grammar as in the poetry project, Mr. Walker chose to wrap up the semester in December with three full days of grammar instruction before the final On-Demand writing assessment. Instead of solely encouraging freewriting in preparing for the prompt on cultural assimilation, Mr. Walker placed grammar worksheets on the podium for students to pick up as they entered the classroom. On the days with just grammar instruction, Mr. Walker provided a 10 to 15 -minute long lecture, covering topics such as how to classify verbs, nouns, and adjectives, as seemed to be missed from the creative project, as well as discussing grammar, sentence mechanics, and punctuation (FN, P. 1, 12/2/16). Afterwards, students were given the remainder of the class period to finish the worksheet assigned. Multiple students asked why learning grammar was "so important," to which Mr. Walker explained the need to pass the "real On-Demand writing assessment and English and Reading sections of the ACT in order to go to college" (FN, P. 2, 12/2/16). Mr. Walker's justification of grammar did not seem to motivate many students to complete the work, such as Jonathan, who sat with a blank worksheet on his desk and stated, "I just need to talk to my counselor about college. I am college and career ready!" (FN, P. 2, 12/2/16). Another student, Brandon, echoed the same sentiment: "Me, too. I need to talk to my counselor" (FN, P. $2,12 / 2 / 16)$. Jonathan, a student who first struggled with grammar in his first practice OnDemand writing assessment, now seemed uninterested in the class entirely, as opposed to his willing attitude earlier in the semester to learn to work with the grammar conventions of Dominant American English. Brandon, typically known to complete his work in a timely 
manner, showed a lack of motivation and chose to take the worksheet home for the weekend (FN, P. 2, 12/2/16).

Instead of ending the semester with a positive culminating experience reflecting on the ideas for critical consciousness and cultural understanding, both Mr. Walker and his students seemingly left for the 2-week break feeling a sense of burn-out from repeated grammar drills. When comparing his experience towards the end of the first semester to the start of the second semester, Mr. Walker noted a conscious personal effort to change his curriculum and attitude: "I already feel like this semester is already going better because I have made distinctive adjustments to my own style and my own approach and that has more to do with lesson planning and my attitude. My attitude gets bad when I'm not having success in the classroom... but once I make those adjustments and we have more success, not just in terms of compliance, but in terms of effort and comprehension, then my attitude is obviously better, too" (Interview, 1/20/17). These "adjustments" were seen through shifts of teaching style and curriculum choices, which would focus more on grammar instruction instead of critical literacy.

\section{Shifting towards a Pedagogy of Grammar Instruction within "Standard American English"}

January 2017 marked the beginning of a new unit, in which Mr. Walker outlined the new expectations of the course for the semester. Due to a number of factors, including the ACT college preparation test in March, the On-Demand writing assessment in April, and the returned results from the Jefferson County Public Schools audit (evaluated in November), the class would be taking a turn towards "standards-based grading," which emphasized greater importance of meeting course standards as gauged by weekly assessments and a lesser focus on daily work: “Assessments: 50\%. Meeting of standards: 20\%. Daily work: 20\%. Attendance and participation: 
$10 \%$ " (FN, P. 1, 1/13/17). In explaining the higher priority of assessments over daily work, Mr. Walker stated, "You can come in my class and turn in each assignment from daily work, but fail the assessments, and not pass. You can do well on the assessments, but choose not to turn in the daily work, and still pass. The choice is yours" (FN, P. 1, 1/13/17). The shift in attitude from a critical literacy perspective that embraced diverse literacies and language customs to that of a grammar instruction guided by Standard American English was evident - the pressures of highstakes testing seemed to inhibit Mr. Walker's ability to utilize literacy education as a platform for social change and civic engagement.

Each Friday, Mr. Walker planned to give an assessment to gauge the students' knowledge of the grammar and writing lessons covered within the week. The assessments were largely multiple-choice, although some included short writing sections in which the students were asked to interact with the text by underlining or crossing out sentences within a paragraph, or writing on one's own topic and concluding sentences to conjoin paragraphs together (FN, P. 1, 1/13/17). The assessments were then graded and returned the following Monday, with the correct answers marked and graded. Some of the lessons covered in January included "how to identify nouns, verbs, and adjectives within a sentence," "how to write a topic sentence," "how to write a concluding paragraph," "how to identify irrelevant sentences within a paragraph," and "correct usages of punctuation" (FN, P. 1, 1/10/17). The lessons were taught in isolation from literature, utilizing worksheets and workbooks instead of prompting students for critical discussion, as was observed in Mr. Walker's ELA Unit 2.

With the school's focus on the ACT college preparation exam and On-Demand writing assessment, Mr. Walker intentionally framed his lesson plans to prioritize an emphasis on the grammar instruction "necessary to pass the ACT English and Reading, as well as score well on 
the On-Demand" (Interview, 1/20/17). As noted by Mr. Walker, the English section of the ACT exam focuses heavily on English usage and mechanics, such as grammar, sentence structure, rhetorical skills, writing style, and organization. The Reading section emphasizes reading comprehension across a variety of texts (Interview, 1/20/17). The questions in this section cover plot details, the main idea, the author's or character's point of view, vocabulary, and cause-andeffect. In regards to the On-Demand writing assessment, Mr. Walker notes that "grammar, usage, and mechanics" are assessed alongside the elements of writing within the areas of "developing ideas, using supporting details, and organization" (Interview, 1/20/17; FN P. 1, 1/18/17).

According to Mr. Walker, writing instruction and the mechanics of grammar are what needed to be prioritized in order to score well on the mandated assessments, such as the ACT, which "has a huge impact on their [the students'] futures, especially if they want to go to college" (Interview, 1/20/17). Mr. Walker deemed grammar instruction in isolation as a "necessary evil," acknowledging that a counterargument can be made that he is "teaching English ... not teaching a test prep course," yet stating his frustration that his students needed to start at the very basics of grammar instruction, even referring back to elementary-level worksheets, in order to become better writers (FN, P. 1, 1/18/17; Interview, 1/20/17). When asked why he noticeably shifted his pedagogy away from the critical literacy-based pedagogy in Unit 2, he explained that because tests such as the ACT or On-Demand writing assessment do not necessarily test for critical thinking of social issues, his students would pale in comparison to other students receiving literacy training in English Language Arts classrooms that do prioritize grammar instruction and writing mechanics (Interview, 1/20/17). The values placed on the latter further complicate the literacy education debate that exists in valuing grammar standards over developing critical consciousness of literature and language. 


\section{Student Preferences for Critical Literacy Over Grammar Instruction}

When the students returned to Mr. Walker's class following the two-week break between ELA Units 2 and 3, many students seemed quite confused and even expressed frustration towards the shift in curriculum, with one student, Michael, commenting, "Why do we have to do this? We already know this" (FN, P. 1, 1/5/17). The comment was bypassed by Mr. Walker, who explained, "I'm sure this is review for many, but it is necessary" (FN, P. 1, 1/5/17). A few students scattered across the classroom were noticeably checked out of the lessons, with one student listening to music and another scrolling through social media on her smartphone (FN, P. $1,1 / 5 / 17)$. The following week, even students who were initially enthusiastic about returning to Mr. Walker's class showed resistance to completing the work and assessments, as Serena, a diligent student and talented writer, confronted Mr. Walker: "Y'all and all these assessments is a little bit too much" (FN, P. 2, 1/11/17). Students who sat nearby Serena nodded in agreement, pushing their work to the sides of their desks and choosing to interact with their smartphones instead. Some students even found it surprising that others were choosing to be compliant with grammar instruction, as Kevin turned to Antonia: “Oh, Antonia, you're actually doing your work. I don't even think I did that. Nope, I definitely didn't” (FN, P. 2, 1/11/17). Many students showed a lack of interest in the work, as fewer completed worksheets were turned in at the end of the class period as the week progressed. The pedagogical focus on grammar instruction and high-stakes testing seemed to have an overall negative effect on students' motivation to complete their work or engage in fruitful discussion.

To survey overall responses towards critical literacy pedagogy in practice, ten focal students were asked in interviews what they perceived as the most useful skills learned from Mr. Walker's $11^{\text {th }}$ grade English Language Arts course. In a general consensus, 7 out of 10 students 
referred to Mr. Walker's sense of civic engagement and interest in politics, showing their excitement towards discussing issues such as racism and poverty. Four of the 10 students seemed impressed with Mr. Walker's ability to relate on a personal level while also finding a way to identify with the text assigned. Two out of 10 students interviewed referred to Mr. Walker's sense of respect within the classroom, describing that the most important lesson learned was not one from literature, but instead, from exemplifying character. One student, Daniel, abstained from answering the question of identifying "the most useful skill," but instead offered advice to Mr. Walker as an English Language Arts teacher. A student who typically does not participate in class discussion, Daniel stated the need for English grammar instruction and did not desire to discuss politics within the classroom. Instead, Daniel argued that literacy instruction should be more apolitical in nature, and that "social studies classes should be covering politics" (Interview, $1 / 18 / 17)$

Thus, the majority of students reported that they benefitted more from the aims of critical literacy pedagogy than the grammar instruction. By being exposed to a mindset of critical consciousness and developing cultural understanding through literacy education, most students in the classes observed were able to gain valuable insight from engaging in discussions surrounding issues of social injustice. Other students, who did not seem to be as open to the idea of literacy education, often showed indifference in classroom discussions and group activities, perhaps predicting future political apathy in a community setting. Although the futures of the student participants cannot be determined, it is my hope as a participant observer that these students will adapt these skills of questioning the dominant discourse or of those around them, while also embracing diverse cultural identities. 


\section{Discussion}

The pressures of high-stakes testing are certainly familiar to many teachers across the nation, yet especially to those who strive to teach in a way that works directly against the testing system and view it as an unjust structure of power that promotes inequity. This case study brought attention to the difficulties faced by a teacher who, at first, informed his teaching practice with critical literacy strategies, and then transitioned to a style of instruction that seemed more "fitting" to the harsh reality of high-stakes testing and the opportunities it can withhold or give to students from marginalized communities. This research adds a more complicated perspective to case studies which present critical literacy pedagogues meeting their aims of critical consciousness and cultural competency with relative ease. For teachers faced with similar struggles in negotiating grammar instruction and critical literacy, Mr. Walker's experience confirms the felt frustrations of social justice oriented educators.

\section{Implications for Teaching}

This study provides some directions for those interested in breaking down the language privilege given to Dominant American English in multilingual or multidialectal classrooms. For example, Mr. Walker's flexible use of language and cultural understanding with his students can be taken a step further and implemented within grammar lessons that inform students of both Dominant American English and African-American Language (AAL), or other English dialects, in a way that gives contexts to the ideologies at play. In such lessons, the teacher could discuss the rules of both dialects, but illustrate and emphasize that "good writing does not depend on 'correct' grammar" (Young, et al., 2014; p. 21). Teacher resources exist that promote a mixed use of language in instruction, such as lessons plans which may cover aspects of AAL, and the grammatical rules for "Like" or "Ain't" (Brown, 2009). In a more critical approach, it may be 
beneficial to inform students on the meanings of linguistic prejudice, profiling, and privilege, all of which may assist in students understanding the teaching of grammar (Janks, et al., 2013). Further, the teacher can illustrate the power structures of language by asking questions concerning whose language variety is perceived as the standard and how different dialects can disrupt the dominant language.

\section{Implications for Research}

Research has been conducted on strategies to explore issues of language and racial/ethnic identity within the diverse English classroom, as exemplified in case studies of two teachers presented by Amanda J. Godley, Adam Loretto, and Brian D. Carpenter in utilizing "counternarratives" and a daily editing activity known as "Daily Oral Language." Mr. Walker's experience of "mixing language dialects" draws similarities to that of Mrs. Allen, who rejects the "master narrative" of language in perpetuating the assumption of proper English as "talking White” and slang as “talking Black” (Godley and Loretto, 2013, p. 2). Similarly, Cindy's critical practice of Daily Oral Language, a strategy that orally reviews sentences for grammar, punctuation, and spelling, offers an interesting perspective on the ideologies that Mr. Walker identifies through his teaching of literary texts and "resistance readings," as it builds further on these practices to promote the English teacher in helping "students of color both to master the dominant discourses and transform them" (Delpit, 1995, p. 163, qtd. in Godley, et al., 2007, p. 107). These case studies show that it is possible to teach literacy in a way that blends grammar instruction and challenges dominant discourses.

However, even with groundbreaking practices of critical literacy to be conscious of language ideology, there still exists the potential pressures of high-stakes testing. In addressing the system of language oppression through high-stakes testing, this case study, alongside many 
others, further articulate the need for more research, perhaps through more extensive studies, which cover at least an entire school year or longer, or comparative case studies, which analyze how other critical literacy pedagogues navigate the same pressures of testing. In addition, it is important to develop an intersectional approach to this extended study, which cover more than just the racial and ethnic identity assumptions presented through literature and language, but also prejudices that exist according to gender, sexuality, religion, socioeconomic status, and more.

The literacy education debate, however, will continue to take place as long as there exists an educational atmosphere that privileges Dominant American English over other language dialects and attempts to fit the present-day multiculturalism of the United States within the limits of "the age of accountability." It is important to note that research has been conducted on these restrictions as they curb critical literacy pedagogy, with the most recent theory being that of “culturally sustaining pedagogy," coined by Paris as a more pluralist teaching model that goes beyond the affirmation of cultural identity and social consciousness in questioning the dominant culture and language. Paris argues that teachers must "support young people in sustaining the cultural and linguistic competence of their communities while simultaneously offering access to dominant cultural competence (Paris, 2012). Culturally sustaining pedagogy attempts to alleviate issues of power between dominant and marginalized discourses with an increased focus on sustaining "linguistic, literate, and cultural pluralism as part of the democratic project of schooling" (Paris, 2012, p. 93). In future research, one can study the efficacy of culturally sustaining pedagogy, a step further in dismantling the power structure sustained by the dominant culture, by utilizing new strategies that build on the work of critical pedagogy, culturally relevant pedagogy, and critical literacy pedagogy, in order to continue to find ways to work towards educational justice and equity. 


\section{Appendix A}

\section{Interview Questions for Students}

1. Tell me a bit about yourself. How would you describe yourself as a student?

2. How would you describe Riverdale High School? What do you like about this school? What would you want to change about this school?

3. How would you describe Mr. Walker as a teacher? How do you feel about the way Mr. Walker teaches English?

4. What are the most useful skills gained from Mr. Walker's $11^{\text {th }}$ grade English Language Arts class?

5. How do you feel about the readings in this class?

6. Describe any instances in this class when you were encouraged to think critically about a certain topic.

7. Describe a time in this class when you felt as if your beliefs or views were challenged by something you have read.

8. Do you ever think about conversations from this class when you're not in school? If so, what is an example?

\section{Appendix B}

\section{$\underline{\text { Interview Questions for Instructor }}$}

1. What is your education and teaching background?

2. Are you familiar with critical literacy or critical pedagogy?

3. How do you promote critical thinking within literature?

4. Why do you feel as if taking a critical perspective is important to your students' learning?

5. What is the most rewarding/difficult aspects of teaching with this perspective?

6. What pressures do you face as a teacher?

7. How do you adapt to the diverse needs of your students?

8. How is your work as a teacher at Riverdale High School different from other teachers in this school or other schools in the district? 


\section{Appendix C}

A Raisin in the Sun - On Demand Writing (Informative)

Prompt: In the play A Raisin in the Sun we see the Youngers experience racial housing discrimination as it occurred in the 1950's as the family is basically told it is not wanted in the neighborhood of Clybourne Park, which it has recently moved to. Unfortunately, such experiences were not uncommon for people of color during this era of American history. In the modern era, people of color rarely experience blatant discrimination when it comes to housing; however; racial housing discrimination does still occur in much more subtle forms.

Task: Compose an informative on demand (5 paragraph) essay. Use the excerpt from the play that was read in class with the more recent article on housing discrimination in order to draw conclusions about housing discrimination as it existed in the 1950's compared to the more modern forms of racial housing discrimination that can still occur today.

- Make sure you have a thesis statement in your first paragraph.

- All paragraphs should have a topic sentence.

- Include text evidence from the play, article, or both in each body paragraph.

- Thoroughly explain your observations and conclusions. 


\section{Appendix D}

\section{CREATIVE PROJECT}

You are going to write a poem using the structure of 'A Dream Deferred.' Use the back of this paper to complete all four steps. Once you have a complete draft, show your work to your teacher and write your final draft of your poem on a colored sheet of paper.

1. First, think of one of YOUR dreams that has been 'deferred.' It could be something past or present, something important to you or important to other people, something global or something local, a serious topic or something more lighthearted.

2. What colors do you think of when you think of this dream being deferred?

3. List verbs, nouns and adjectives that you might use in similes in order to create a coherent image and color scheme.

4. Write the poem. Make sure to write it EXACTLY in the style of Langston Hughes. It should be the same amount of sentences and questions, but should be specific to your own dream.

\section{A Dream Deferred \\ By Langston Hughes}

What happens to a dream deferred?

Does it dry up

like a raisin in the sun?

Or fester like a sore-

And then run?

Does it stink like rotten meat?

Or crust and sugar over-

like a syrupy sweet?

Maybe it just sags

like a heavy load.

Or does it explode? 


\section{References}

Alim, S. H., \& Baugh, J. (Eds.). (2006). Talkin’ black talk: Language, education, and social change. New York: Teachers' College Press.

Applebee, A. N. (1993). Literature in the Secondary School: Studies of Curriculum and Instruction in the United States. Urbana, IL: National Council of Teachers of English.

Borsheim-Black, C. (2015). “It's Pretty Much White”: Challenges and Opportunities of an Antiracist Approach to Literature Instruction in a Multilayered White Context. Research in the Teaching of English, 49, 407-429.

Brown, D. W. (2009). In Other Words: lessons on grammar, code-switching, and academic writing. Portsmouth, NH: Heinemann.

Chubbuck, S. M. (2004). Whiteness enacted, whiteness disrupted: The complexity of personal congruence. American Educational Research Journal, 41(2), 301-333. doi:10.3102/00028312041002301

Colombo, G., Cullen, R., \& Lisle, B. (2010). Rereading America: Cultural contexts for critical thinking and writing (8th ed.). Boston, MA: Bedford/St. Martins.

Comber, B. (2014). Critical literacy and social justice. Journal of Adolescent \& Adult Literacy, $58(5), 362-367$.

Delpit, L. (1986). Skills and other dilemmas of a progressive black educator. Harvard Educational Review, 56(4), 379-386. doi:10.17763/haer.56.4.674v5h1m125h3014 
Doyle, R. W. (2005). Recalling the Record: A Documentary History of the African-American Experience Within the Louisville Public School System of Kentucky. Chapel Hill, NC: Professional Press.

Dynarski, M. (2015). Using Research to Improve Education under the Every Student Succeeds Act. Evidence Speaks Reports, 1(8), 1-6.

English/Language Arts Curriculum. (2017). Retrieved February 28, 2017, from Jefferson County Public Schools, https://www.jefferson.kyschools.us/learning/curriculum/english

Enoch, J. (2008). Refiguring rhetorical education: Women teaching African-American, native American, and Chicano/a students, 1865-1911 (3rd ed.). New York, NY, United States: Southern Illinois University Press.

Frankenberg, R. (1993). The social construction of whiteness: White women, race matters. Minneapolis: University of Minnesota Press.

Freire, P. (2000). Pedagogy of the Oppressed. New York: Continuum.

Giroux, H. (1993). Literacy and the politics of difference. In C. Lankshear \& P. L. McLaren (Eds.), Critical Literacy: politics, praxis, and the postmodern (pp. 367-377). Albany, NY: State University of New York Press.

Godley, A. J., Carpenter, B. D., \& Werner, C. A. (2007). “I'll speak in proper slang”: Language ideologies in a daily editing activity. Reading Research Quarterly, 42(1), 100-131. doi:10.1598/rrq.42.1.4

Godley, A. J., \& Loretto, A. (2013). Fostering counter-narratives of race, language, and identity in an urban English classroom. Linguistics and Education, 24(3), 316-327. doi:10.1016/j.linged.2013.03.006 
Grant, C. A. (2004). Oppression, privilege, and high-stakes testing. Multicultural Perspectives, 6(1), 3-11. doi:10.1207/s15327892mcp0601_2

Hill, M. L. (2009). Beats, Rhymes, and Classroom Life: Hip-Hop Pedagogy and the Politics of Identity. New York: Teachers College Press.

Horton, M., Bell, B., Gaventa, J., \& Marshall, J. P. (1990). We Make the Road by Walking: Conversations on Education and Social Change. Philadelphia: Temple University Press.

Hoschschild, J. L. (1985). Approaching Racial Equality Through Indirection: The Problem of Race, Class, and Power. Yale Law \& Policy Review, 4(2), 307-330.

Houchen, D. (2012). "Stakes is high": Culturally relevant practitioner inquiry with AfricanAmerican students struggling to pass secondary reading exit exams. Urban Education, 48(1), 92-115. doi:10.1177/0042085912456845

Janks, H., Dixon, K., Ferreira, A., Granville, S., \& Newfield, D. (2013). Doing critical literacy: Texts and activities for students and teachers. New York: Routledge.

Jefferson County Public Schools 2015-2016 Current Enrollment by Race and Gender. (2015). Jefferson County Public Schools Data Book 2015-2016.

Jefferson County Public Schools 2015-2016 Free/Reduced Lunch Participation. (2015a). Jefferson County Public Schools Data Book 2015-2016.

Jefferson County Public Schools 2015-2016 Free/Reduced Lunch Participation. (2015b). Jefferson County Public Schools Data Book 2015-2016.

Kearns, L.-L. (2013). "The construction of "illiterate" and "literate" youth: The effects of highstakes standardized literacy testing." Race Ethnicity and Education, 19, 1-20.

Kozol, J. (1991). Savage inequalities: Children in America's schools. New York: Crown Pub., New York, New York, U.S.A. 
Ladson-Billings, Gloria. (1995). Toward a theory of culturally relevant pedagogy. American Educational Research Journal, 32(3), 465-491. doi:10.2307/1163320

Ladson-Billings, Gloria (1992). Reading between the lines and beyond the pages: A culturally relevant approach to literacy teaching. Theory Into Practice, 31(4), 312-320. doi:10.1080/00405849209543558

Ladson-Billings, Gloria (1995). But that's just good teaching! The case for culturally relevant pedagogy. Theory Into Practice, 34(3), 159-165. doi:10.1080/00405849509543675

Lindsay, J. L. (2007). Talking whiteness: Representations of social justice in One school. The Urban Review, 39(4), 425-453. doi:10.1007/s11256-007-0060-Z

Miller, K. D. (2004). Plymouth rock landed on us: Malcolm X's whiteness theory as a basis for alternative literacy. College Composition and Communication, 56(2), 199-222. doi:10.2307/4140647

Morrell, E. (2008). Critical literacy and urban youth: Pedagogies of access, dissent, and liberation. New York, NY: Routledge.

Paris, D. (2012). Culturally sustaining pedagogy: A needed change in stance, terminology, and practice. Educational Researcher, 41(3), 93-97.

Paris, D., \& Alim, H. S. (2014). What are we seeking to sustain through culturally sustaining Pedagogy? A loving critique forward. Harvard Educational Review, 84(1), 85-100.

Perry, T. (1993). Toward a theory of African-American student achievement. Boston, MA: Center on Families, Communities, Schools and Children's Learning, Wheelock College. Rouland, K., Matthews, J. S., Byrd, C. M., Meyer, R. M. L., \& Rowley, S. J. (2014). Culture Clash: Interactions between Afrocultural and Mainstream Cultural Styles in Classrooms 
Serving African-American Students. Interdisciplinary Journal of Teaching and Learning, 4(3), 186-202.

Vasquez, V. M., Tate, S. L., \& Harste, J. C. (2013). Negotiating Critical Literacies with Teachers: Theoretical Foundations and Pedagogical Resources for Pre-Service and inService Contexts. New York, NY: Routledge.

Winn, M. T., \& Behizadeh, N. (2011). The right to be literate: Literacy, education, and the school-to-prison pipeline. Review of Research in Education, 35(1), 147-173. doi: $10.3102 / 0091732 \times 10387395$

Young, E. (2010). Challenges to conceptualizing and Actualizing culturally relevant Pedagogy: How viable is the theory in classroom practice? Journal of Teacher Education, 61(3), 248260. doi:10.1177/0022487109359775

Young, V. A., Barrett, R., Young-Rivera, Y., Lovejoy, K. B. (2014). Other People's English: Code-Meshing, Code-Switching, and African-American Literacy. New York, NY: Teachers College Press. 